\title{
Life cycle engineering and management methods for designing hybrid structures - cases, potentials, and challenges
}

\author{
Uwe Götze ${ }^{1}$, Christina Symmank ${ }^{1)}$, Anja Schmidt ${ }^{1)}$ \\ 1) Chair of Management Accounting and Control, bwl3@wirtschaft.tu-chemnitz.de, Chemnitz \\ University of Technology, Thüringer Weg 7, 09126 Chemnitz, Germany
}

\section{Keywords}

Hybrid Structures, Innovation Management, Life Cycle Engineering (and Management), Lightweight Structures, Sustainability

\begin{abstract}
Designing sustainable systems that take into account production factors, processes, and/or products is becoming more and more important. It is therefore the focus of research projects such as the Federal Cluster of Excellence EXC 1075 "MERGE Technologies for Multifunctional Lightweight Structures", which strives for resource-efficient lightweight construction and especially the design of hybrid structures. To support this challenging task, the Life Cycle Engineering (LCE) approach is recommended. However, a sustainable design requires an economic or rather management orientation of the engineering activities, which is underrepresented in the LCE concept. Therefore, it is proposed to extend the LCE to a Life Cycle Engineering and Management (LCEM) concept. Since both concepts are relatively new, only a few cases of application are available. Therefore, this paper describes and analyzes cases - especially on the basis of MERGE research objects -, to which LCE and LCEM are applied, identifies potentials and challenges, and derives consequences for further research activities. This highlights the relevance of LCE and LCEM for research projects, especially regarding the transformation of an invention into a successful innovation.
\end{abstract}

\section{Introduction}

The quest for sustainability is gaining more and more importance both in the economy as well as in society - the trend towards sustainable solutions is exemplified by the pursuit of resource efficiency in general, lightweight construction, and in particular the design of hybrid structures (processes, products, and composite materials) researched in the Federal Cluster of Excellence EXC 1075 "MERGE Technologies for Multifunctional Lightweight Structures". The German term "Nachhaltigkeit" (sustainability) - first used in old German language by VON CARLOWITZ who referred to the cultivation of the Saxon forest [1] - implies a long-term perspective. Consequently, the engineering as well as management of any type of system, including those researched in MERGE, should be directed towards the entire life cycle.

Life cycle-orientation is one of the guiding principles of the concept of Life Cycle Engineering (LCE). LCE is defined as "engineering activities which include: the application of technological and scientific principles to the design and manufacture of products with the goal of protecting the environment and conserving resources, while encouraging economic progress, keeping in mind the need for sustainability, and at the same time optimizing the product life cycle and minimizing pollution and waste" [2]. Due to these characteristics, LCE is a very promising approach for the design of sustainable systems - consisting of production factors, processes, and/or products - and especially for the design of hybrid structures. However, despite the inclusion of economic evaluations in the above definition of LCE, a review of the literature showed that the management perspective is not strongly represented in LCE approaches [3]: This motivates the extension of LCE to a Life Cycle Engineering and Management (LCEM) concept. This concept includes management tasks and methods in a more balanced way in 
order to improve the probability and extent of commercial success of innovative and ecologically beneficial products and processes $[3,4]$.

At present, LCE is not a well-established and unambiguously defined method, but rather a kind of framework covering a variety of different approaches. Application cases of LCE are not widespread and it is so far not (explicitly) established in many companies. LCEM is a very young concept that is still in its infancy. Application cases of LCEM hardly exist. This lack of application cases for LCE/LCEM as well as both concepts' relevance for research projects and particularly for the Cluster of Excellence MERGE, especially with regard to bridging the gap between invention and successful innovation, motivate this paper: Its intention is to demonstrate and review how economic evaluation methods of LCE and LCEM have been applied in MERGE. By describing and analyzing a number of cases, possible ways of applying economic evaluation and management methods in a research cluster will be characterized (section 3) and the corresponding potentials and challenges identified (section 4). Finally, the findings and perspectives gained for establishing sustainability-oriented engineering and management instruments are outlined (section 5). The following section provides a basis for these considerations by briefly outlining the characteristics of LCE and LCEM.

\section{Brief characterization of LCE and LCEM}

The rather broad definition suggested by JESWIET and the heterogeneity of LCE approaches result in the need to define boundaries and constitutive characteristics of LCE. Based on the definition by JESWIET and a study of LCE literature, PECAS ET AL. suggest the following three necessary conditions for an approach "to be about LCE" [3]:

- Life cycle perspective: A life cycle view has to be explicated and more than one life cycle phase has to be included.

- Engineering perspective: Engineering activities and decisions and/or their support have to be brought into focus.

- Environmental and economic perspective: Environmental as well as economic targets are taken into account.

The heterogeneity of existing LCE approaches also raises the need of structuring them in order to enable a differentiated analysis of its state of the art as well as the positioning of individual approaches within the landscape of LCE. Contributions to structuring the field of LCE have been made by PEÇAS ET AL. [5], UMEDA ET AL. [6], and HAUSCHILD ET AL. [7]. A comprehensive and transparent concept of structuring elaborated in the context of MERGE - is the taxonomy of LCE presented in figure 1.

The taxonomy shows a hierarchical structure with two levels, each consisting of two sub-levels: The first level is a so-called theory leve/ with sub-levels that capture the intended contribution of a publication about LCE and its theoretical foundations. The second level, the design level, is intended to cover the possible activities of LCE and their reference objects. Each of these two sub-levels includes several criteria in order to enable a differentiated characterization of activities and reference objects (for a more detailed description of the derivation of the taxonomy and the taxonomy itself, see [3]).

Using this taxonomy, the state of the art of LCE was characterized on the basis of a comprehensive literature review [3]. The results comprise the lack of empirical studies, the low reference to management theories, the negligence of the social dimension of sustainability, a huge variety of methods suggested for LCE, and the focus on only selected parts of the life cycle in most publications with concrete reference objects, among others. In general, the economic or management dimension is not strongly represented in LCE literature. Above all, some relevant management tasks, customer needs, market potentials, competition- and supply chain-orientation as well as methods such as Target Costing, Business Modeling or cost knowledge management methods are largely neglected (see also [4]). Hence, it seems to be meaningful to foster the management-orientation of LCE by showing ways for its extension by or integration with management-relevant issues neglected so far - towards a Life Cycle Engineering and Management approach (for initial approaches see [4] and some of the cases described and analyzed in the following). 


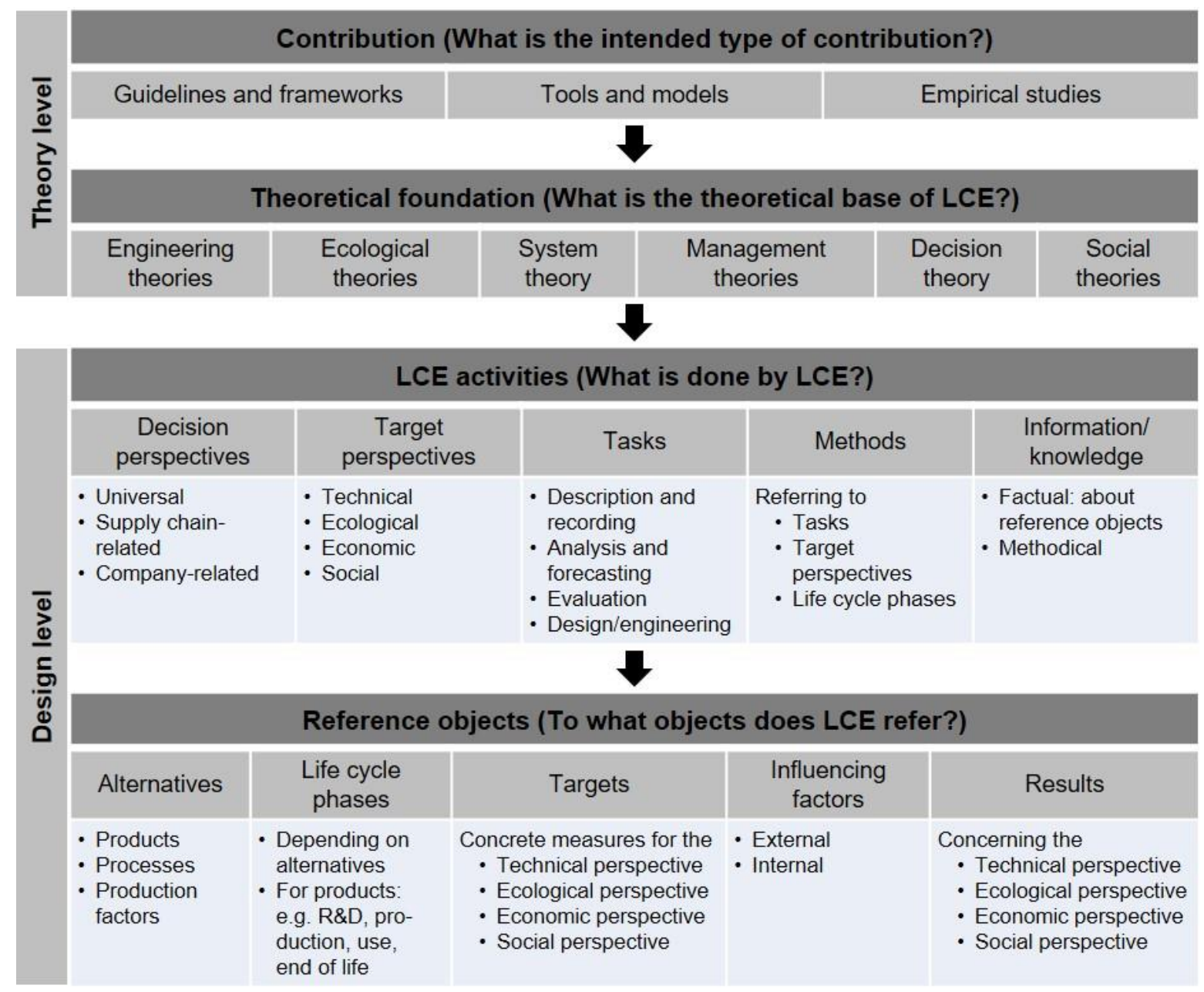

Figure 1: Taxonomy of Life Cycle Engineering [3]

\section{Application cases of management-oriented and life cycle-related methods and models in MERGE}

\subsection{Relevant criteria}

First, the criteria for characterizing the management-oriented and life cycle-related methods applied in MERGE have to be defined. As a basis, the taxonomy described in the previous section is used. However, some of the sub-levels and criteria of the taxonomy do not seem to be useful for a differentiated characterization of the cases. Above all, partly due to the economic background of the paper, all cases have some identical characteristics:

- The clearly predominant intended contribution is the development (and application) of tools and models.

- Therefore, primarily management theories (production theory, cost and cost accounting theory, etc.), decision theory, and some of the basics of system theory are used.

- The decision perspective is always a mixture of a company perspective (since the view of a decision-maker in a fictitious company is taken), a universal perspective (since no concrete company is involved), and, additionally, a research perspective (since the analyzed alternatives as well as some of the data come from a research context). Furthermore, supply chain issues are included if they are highly relevant (but not explicitly with the aim of designing an entire supply chain).

- In each case the primary task is the evaluation of design options. This typically requires description, analysis, and forecasting activities as well. Additionally, indications for the design can be derived from the evaluation results. 
Moreover, the information/knowledge, influencing factors, and results are highly case-specific and hence quite disparate. Therefore, they are not included. Consequently, the following criteria are primarily applied for the subsequent characterization of application cases:

- The target perspective regarded - of course the economic target perspective is dominant, but it seems to be of interest whether and which other target perspectives are taken into account and which way of multi-criteria decision-making is suggested.

- The methods used - being the main topic of this paper due to their high relevance for systematic decision support.

- The alternatives, life cycle phases, and the concrete economic targets considered.

\subsection{Cases}

In this section, the cases considered in this paper are briefly described. For an overview of the cases, see figure 2, which describes the objects, target perspectives, and life cycle phases included as well as the tasks of LCE focused in the cases. The first group of cases to which management-oriented and life cycle-related methods were applied refers to the evaluation of the process-related technologies and different materials for manufacturing three-dimensional contoured thermoplastic sandwich structures (t3S) for the mountain bike component "rocker" (cases 1). This case group was analyzed in three steps, first with a strong focus on an economic target perspective (case 1a) [8] and subsequently with an extended target perspective including technical and ecological targets (cases $1 \mathrm{~b}$ and $1 \mathrm{c}$ ) $[9,10]$. The applied (management and integrated) methods include life cycle models (for structuring the economic and ecological effects), procedure models (for a well-structured, transparent, and systematic evaluation), process-based models (for analyzing the relationship between process input(s) and output(s)), cost accounting methods (for calculating the costs of manufacturing processes and total costs), the net present value (NPV) method (which can also be interpreted as a means of life cycle costing (LCC)) [11], a systematic consideration of the utility in the use phase (by deriving weightdependent price functions), sensitivity analyses (for deriving critical values), and finally ternary diagrams for multi-criteria decision-making. The examined alternatives comprise manufacturing technologies as well as different materials as specific resources that influence the user-relevant weight of the component (as a potential product from the point of view of its manufacturer). Especially in case 1c materials are focused - questioning whether natural fibers used for composites are advantageous as rocker raw materials: For this purpose, four composite material alternatives were evaluated - two with synthetic fibers (glass fiber and carbon fiber) and two with natural fibers (Jute and Ramie); as a baseline an aluminum alloy was used. The economic evaluation focuses on the manufacturing and use phase (case 1a) and the raw material acquisition, manufacturing, (use), and end-of-life (EOL) phase (cases $1 \mathrm{~b}$ and $1 \mathrm{c})$, respectively. The economic target figure is the life cycle profit (case 1a) or the life cycle costs (1b and 1c) - in the latter cases assuming that the effect of the alternatives on revenues is considered in the technical evaluation (above all by the resulting weight of the components). Here, the life cycle profit is measured by NPV, the life cycle costs are calculated as the sum of the annual costs. The annual costs consist of variable costs (e.g. material costs, energy costs) and fixed costs. Fixed costs (resulting from previous or initial investments) are an annuity of the initial investment outlay, calculated by using a capital recovery factor. Besides the evaluation of the alternatives, some indications for design activities are derived - especially the critical weight of a component manufactured with the innovative t3Stechnology (1a). Additionally, supply chain aspects are included in the evaluation, particularly in cases $1 \mathrm{~b}$ and $1 \mathrm{c}$ (for details and results of the evaluations see $[8,9,10]$ ).

The second group of cases concerns the integration and use of active flow control (AFC) devices and passive sensors in rotor blades of wind turbines as an example of the realization of smart structures [4, $12,13,14,15]$. In all cases, an economic target perspective is focused (based on technical results). For AFC devices (case 2a), life cycle models, NPV/LCC, and sensitivity analyses are primarily used to build up a life cycle profit model and derive a critical value formula for the necessary increase in energy yield depending on the additional life cycle costs of the AFC devices (this could be thought of as an element of Target Costing). Regarded alternatives are AFC devices and their design options, all relevant life cycle phases are included, and the concrete target measure is the life cycle profit again [12]. Additionally, first elements of business models for AFC devices, their components and complementary services are 
identified [4]. In the case of passive sensors (2b), life cycle models were also applied to outline possible cost and revenue effects, taking into account all life cycle phases.

Furthermore, the life cycle profit calculated by the NPV method is also recommended as an economic target figure for the life cycle-related evaluation [15]. However, for passive sensors, the design task - in the sense of promoting the innovation and market success - is the main focus. Consequently, the suggested methods comprise an Integrated LCE and Business Modeling [4] and an Integrated Technology, Market, and User Analysis to identify promising areas of application (condition monitoring in wind turbines (e.g. for ice detection) as well as the use in car components or structural health monitoring of buildings). The focused alternative is the product-related technology of passive sensors in combination with specific fields of application, all life cycle phases are considered conceptually; economic target measures are strategic success factors and the NPV $[13,14]$.

\begin{tabular}{|c|c|c|c|c|c|c|}
\hline & & & Object(s) & Target perspectives & Life cycle phases & $\begin{array}{c}\text { Focused } \\
\text { Tasks of LCE }\end{array}$ \\
\hline \multirow{3}{*}{$\begin{array}{l}5 \\
\text { 윽 } \\
0 \\
0 \\
0 \\
0 \\
0 \\
0 \\
0 \\
0\end{array}$} & \multirow{3}{*}{$\begin{array}{c}\text { Manufacturing } \\
\text { three-dimensional } \\
\text { contoured thermo- } \\
\text { plastic sandwich } \\
\text { structures (t3S) for } \\
\text { the mountain bike } \\
\text { component } \\
\text { "rocker" }\end{array}$} & $1 a$ & $\begin{array}{l}\text { Material-process technology } \\
\text { alternatives }\end{array}$ & $\begin{array}{l}\text { - Economic (life cycle profit) } \\
\text { - (Technical) }\end{array}$ & $\begin{array}{l}\text { Manufacturing, use, and } \\
\text { end-of-life }\end{array}$ & Evaluation \\
\hline & & $1 b$ & $\begin{array}{l}\text { Material-process technology } \\
\text { alternatives }\end{array}$ & $\begin{array}{l}\text { - Economic (life cycle costs) } \\
\text { - Technical } \\
\text { - Ecological }\end{array}$ & $\begin{array}{l}\text { Material acquisition, } \\
\text { manufacturing, use, and } \\
\text { end-of-life }\end{array}$ & Evaluation \\
\hline & & $1 \mathrm{c}$ & Material alternatives & $\begin{array}{l}\text { - Economic (life cycle costs) } \\
\text { - Technical } \\
\text { - Ecological }\end{array}$ & $\begin{array}{c}\text { Raw material acquisition, } \\
\text { manufacturing, and } \\
\text { end-of-life }\end{array}$ & Evaluation \\
\hline \multirow{2}{*}{ 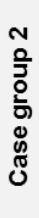 } & \multirow{2}{*}{$\begin{array}{l}\text { Realization of } \\
\text { smart structures: } \\
\text { Integration and } \\
\text { usage of devices } \\
\text { and sensors in } \\
\text { rotor blades of } \\
\text { wind turbines }\end{array}$} & $2 a$ & $\begin{array}{l}\text { Active flow control (AFC) device } \\
\text { design alternatives in rotor blades } \\
\text { of wind turbines }\end{array}$ & - Economic (life cycle profit) & $\begin{array}{l}\text { Design, manufacturing/ } \\
\text { assembly, usage/service, } \\
\text { and end-of-life }\end{array}$ & $\begin{array}{l}\text { Evaluation } \\
\text { (Design) }\end{array}$ \\
\hline & & $2 b$ & $\begin{array}{l}\text { Passive sensors in rotor blades of } \\
\text { wind turbines }\end{array}$ & $\begin{array}{l}\text { Economic (life cycle profit; } \\
\text { strategic success) }\end{array}$ & $\begin{array}{l}\text { Design, manufacturing/ } \\
\text { assembly, usage/service, } \\
\text { and end-of-life }\end{array}$ & Design \\
\hline \multirow{5}{*}{$\begin{array}{l}\text { m } \\
\text { 을 } \\
\text { 인 } \\
0 \\
0 \\
0 \\
0 \\
0\end{array}$} & \multirow{5}{*}{$\begin{array}{l}\text { Hybrid technolo- } \\
\text { gies and process } \\
\text { chains for manu- } \\
\text { facturing hybrid } \\
\text { structures }\end{array}$} & $3 a$ & $\begin{array}{l}\text { Hybrid vs. conventional process } \\
\text { chain for manufacturing hybrid } \\
\text { metal/plastic structures }\end{array}$ & $\begin{array}{l}\text { - Economic (costs) } \\
\text { - Ecological }\end{array}$ & Manufacturing & Evaluation \\
\hline & & $3 b$ & $\begin{array}{l}\text { Production of thermoplastic foams } \\
\text { by injection molding technology }\end{array}$ & $\begin{array}{l}\text { - Economic (profit) } \\
\text { - Technical }\end{array}$ & Manufacturing & Evaluation \\
\hline & & $3 c$ & $\begin{array}{l}\text { Design of actuators for integration } \\
\text { into heterogeneous composite } \\
\text { structures and actuator } \\
\text { manufacturing technologies }\end{array}$ & $\begin{array}{l}\text { - Economic (costs) } \\
\text { - Technical }\end{array}$ & Design, manufacturing & $\begin{array}{l}\text { Evaluation } \\
\text { (Design) }\end{array}$ \\
\hline & & $3 d$ & $\begin{array}{l}\text { Material alternatives for producing } \\
\text { hybrid laminates }\end{array}$ & $\begin{array}{l}\text { - Economic (costs) } \\
\text { - Technical }\end{array}$ & Manufacturing & Evaluation \\
\hline & & $3 e$ & $\begin{array}{l}\text { Innovative vs. conventional } \\
\text { process chain for manufacturing } \\
\text { sensory hybrid laminates }\end{array}$ & $\begin{array}{l}\text { - Economic (costs) } \\
\text { - Ecological }\end{array}$ & Manufacturing & Evaluation \\
\hline
\end{tabular}

Figure 2: Overview of cases

In the third group of cases, hybrid technologies and process chains for manufacturing hybrid structures are focused. The cases considered include

- a hybrid process chain for manufacturing (cup-shaped) hybrid metal/plastic structures (3a) [16, 17]

- the use of injection molding technology for the production of thermoplastic foams (3b) [18]

- design of actuators for integration into heterogeneous composite structures and actuator manufacturing technologies (3c) [19]

- material alternatives for producing hybrid laminates (3d) [20] and an innovative process chain for manufacturing sensory hybrid laminates (3e) [21]. 
In these cases the evaluation is carried out from an economic target perspective and either from an ecological perspective (substantiated by analyzing the energy efficiency and robustness of the alternatives; cases $3 a$ [17], 3e [21]) or from a technical perspective (by calculating a so-called economic lightweight index (3b [18]) or by best solution mapping (3d [20]), both including technical and economic target figures that are combined by utility value analyses, or by measuring the performance parameters of actuators (3c [19])). The methods used include a procedure model for evaluation (see e.g. [22, 23]), which structures the evaluation activities, MEMPHIS ("Multidimensional Evaluation Method for Process chains of Hybrld Structures") as a version of the procedure model specified for the target dimensions energy efficiency, cost effectiveness, robustness - considered in MERGE (see e.g. [17]), InputThroughput-Output (ITO) models to reveal the relationship between process input(s), parameters and output(s), a cost calculation method (overhead percentage calculation/calculation with activity units), a profit model, the already mentioned economic lightweight index, and best solution mapping based on utility value analyses. The alternatives considered are different types of "conventional" and "innovative hybrid" process chains/technologies. Despite the underlying life cycle perspective, the evaluation is focused on the manufacturing phase due to the following assumptions: The economic effects of previous life cycle phases are incorporated in the input factor prices and the output of the alternatives is identical or similar (and therefore negligible) or can be measured by revenues or values of technical attributes determinable with respect to the manufacturing phase. It seems debatable whether these cases are "about LCE" (see the conditions formulated in section 2); however, for sake of completeness and due to the potential contribution of process chain assessments to a life cycle-related evaluation, they are included here. The economic target figure is either costs (if the output is almost identical or differences are measured by a technical target figure) (cases 3a, 3c, 3d, and 3e) or profit (case 3b). It has already been mentioned that the assessment of process chains or process technologies contributes to a life cycle-related evaluation. This is proven by the relationships between the cases and objects considered: For example, the process chains examined in cases $3 b$ and $3 c$ are developed for manufacturing components with AFC devices (case 2a) and are thus part of the life cycles (see figure 3) and one of the objects of a life cycle-related evaluation.

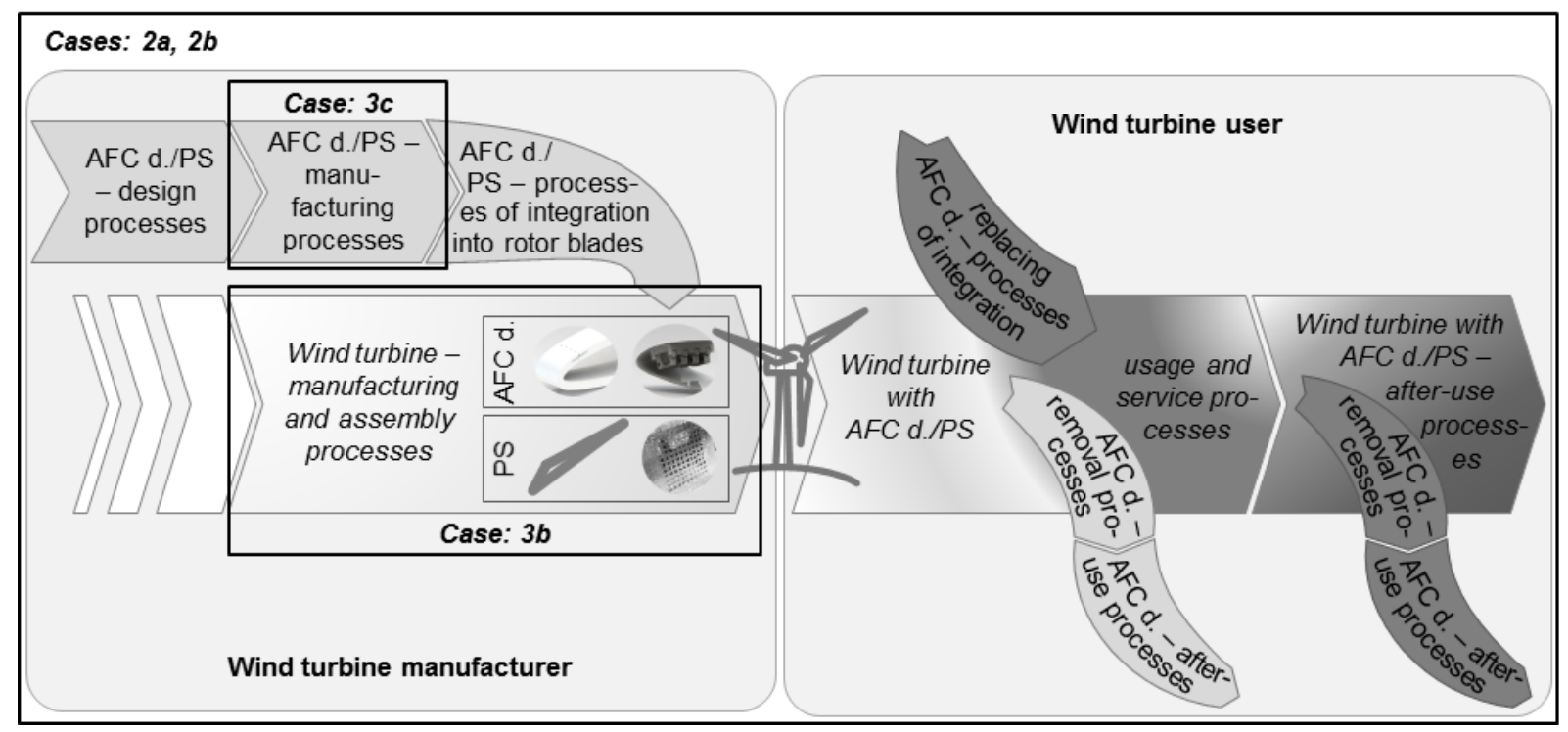

Figure 3: Integrated life cycles of AFC devices (AFC d.)/passive sensors (PS) and wind turbines: related actors and processes (slightly modified adopted from: [12, 15]; image sources: AFC d. [24], PS [25])

In summary, it can be said that only in some of the analyzed cases a technical and/or ecological target perspective was explicitly considered besides the economic one. However, even if a technical and/or ecological perspective is not considered directly, it can be assumed that LCE was applied: In the context of MERGE, a strategy of bivalent resource efficiency is pursued by exploring product and process inventions. Hence, correspondingly focused engineering research activities are also conducted. Furthermore, technical as well as ecological criteria are often indirectly taken into account in the 
economic evaluation (as factors influencing economic criteria). In these cases, a multitude of methods and models are also used, which will be considered in more detail in the following section. The alternatives include resources, processes (or process chains), products, process- or product-related technologies or combinations thereof. Concerning the included life cycle phases, in case groups 1 and 2 all life cycle phases are considered in most cases, in group 3 the manufacturing phase is focused. This goes hand in hand with the use of different economic target figures: life cycle costs are calculated as the sum of the annual costs (with fixed costs as an annuity of the initial investment outlay) or life cycle profit measured as NPV and explicitly considering effects over several periods and life cycle phases (dynamic investment appraisal methods) in the groups 1 and 2 and costs or profit referring to only one representative or "average" period ("static" approach) in group 3. Concerning the concrete economic target figures, a second difference is obvious: If the output of the alternatives is expected to be significantly different, either revenues or cash inflows have to be explicitly included. Hence, the profit or life cycle profit is an adequate target figure or the differences have to be included in an additional target category. In case of equal or similar output, revenues/cash inflows can be neglected and costs or life cycle costs are applicable as target figure.

\subsection{Methods and models}

In this paper, the management-oriented and life cycle-related methods and models applied in MERGE are of particular interest. On the one hand, this is motivated by the high relevance of economic considerations for successful innovations. On the other hand, it is due to the scientific background of the authors in the fields of management accounting and control including decision theory with a strong alignment at the interface to engineering issues. This includes a strong awareness of life cycle-related evaluation and design methods and models such as LCE. Looking at all three case groups, it is obvious that a variety of methods have been used.

Procedure models play a major role in structuring the activities, handling complexity, providing transparency, and fostering communication between different actors (from different disciplines). In some of the cases, which are focused on the evaluation task, procedure models for life cycle- (e.g. cases 1a [8] and 2a [12]) or process chain-related (e.g. case 3a [17]) evaluations proved to be useful. A decisiontheoretical and hierarchically structured procedure model is shown in figure 4.

If the design task is focused, procedure models seem to be helpful for similar reasons. Accordingly, in the second case group an Integrated LCE and Business Modeling (BM) and an Integrated Technology, Market, and User Analysis have been partially applied (see [13]).

Life cycle models are an indispensable basis for identifying the relevant effects of alternatives, building up evaluation models, determining the relevant actors in a supply chain, looking for business model ideas etc. It is therefore not surprising that they are widely used, especially in the cases of the first two groups.

The relationship between the consumption of input factors (resources) and the output is a central determinant of the economic, but also the ecological advantageousness of alternatives. To identify and quantify this relationship, models of the production processes (and possibly other types of processes such as recycling processes) are necessary. In most of the cases of group 1 and 3, either processbased models (e.g. [8, 9, 10]) or ITO models (e.g. [17, 20, 21] have been used for this purpose. With a similar purpose but focused on costs, cost estimation techniques are useful. In general, cost estimation techniques are used to determine the expected costs of novel alternatives (which have not yet been realized) based on analytical or statistical functions, the relationship to similar alternatives realized in the past, expert consultations, etc. (see e.g. [27]). Here, for example, they were used in case 3e [21]. Additionally, cost calculation schemes are necessary to determine costs as a target figure or as an input for the profit calculation or a life cycle-related NPV calculation. For the examined cases the calculation scheme of the overhead percentage calculation and the method of calculation with activity units were applied (e.g. cases 3a [17], 3d [20], and 3e [21]). 


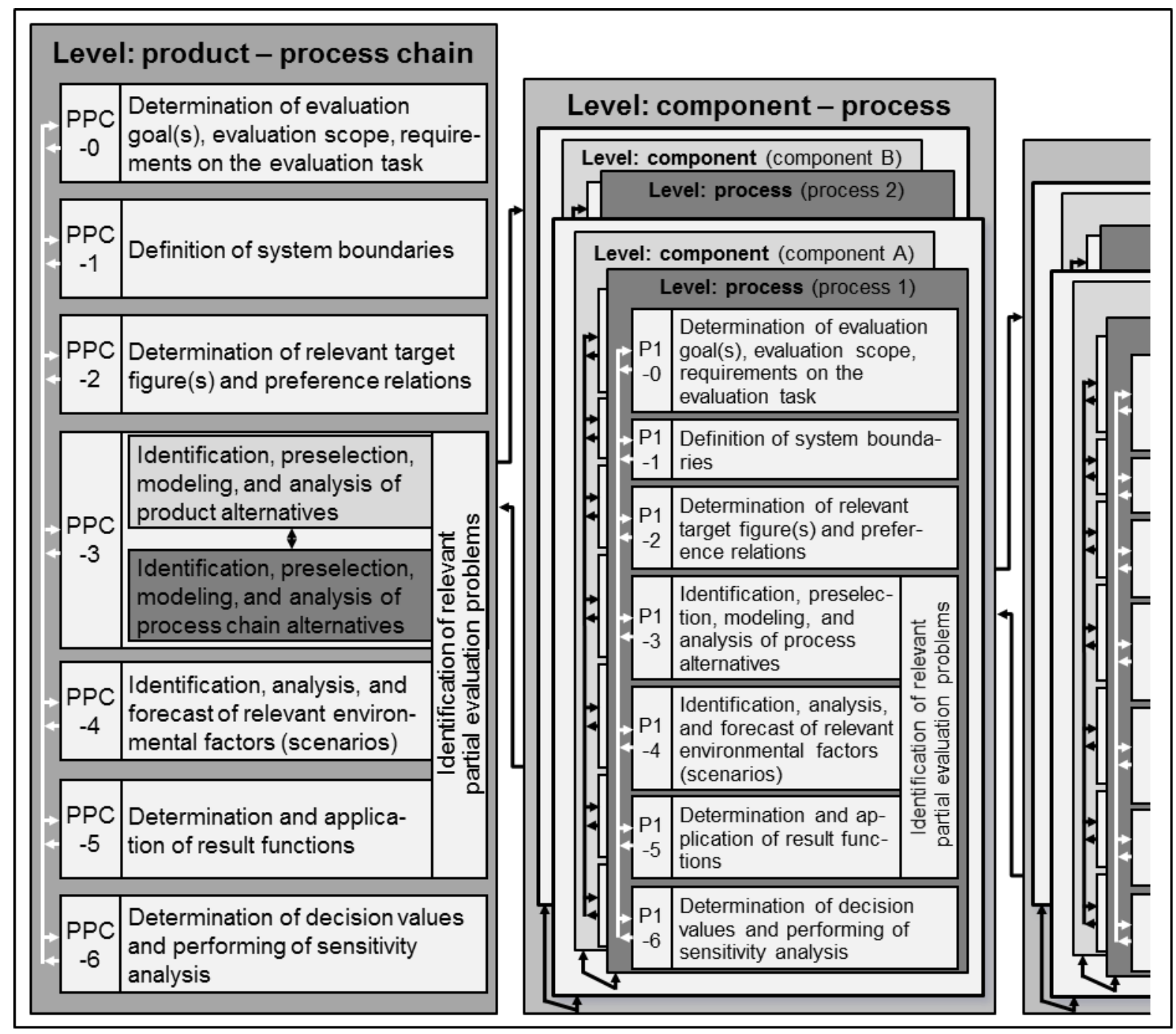

Figure 4: Procedure model for evaluation [22, 23, 26]

If the evaluation spans more than one life cycle phase and period, methods of dynamic investment appraisal (and the corresponding life cycle costing) should be used. The most prominent of these methods is the NPV method. Here, this method was applied to the evaluation tasks of cases 1a and 2a. In these cases, only the cash flow differences between the alternatives were regarded and a differential $N P V$ was calculated. Limiting the analysis to the differences between alternatives and/or the most important effects (instead of calculating the total costs or profits) has proven useful in some other cases as well (e.g. 3b, 3c). In cases $1 \mathrm{~b}$ and $1 \mathrm{c}$, the annuity method was used.

In some cases the output of the alternatives is significantly different. Then it is necessary to apply methods for evaluating the outputs or output differences. In this way, their utility and/or the corresponding differences of revenues and/or cash inflows can be determined. In the regarded cases output differences were considered by taking a technical perspective (cases 1b, 1c, 3b, and 3d) or by including revenues or cash inflows in a (life cycle) profit model (cases 1a, 2a, and 3b). In the latter case, it is necessary to apply methods for estimating the revenues (or revenue differences) resulting from the output differences. For the valuation of output volume differences, market or regulated prices can be used (e.g. for wind energy in case 2a of group 2). If other output characteristics are different, it is necessary to estimate the relationship between these characteristics and the realizable prices. Therefore, an analysis of the weight-dependent prices of mountain bikes was employed in case $1 \mathrm{a}$. In general, weight reductions are honored in the automotive and the aircraft industry, too. For example, for a family car, the monetary benefit per $\mathrm{kg}$ of weight saving is estimated at $1-2 €$. For civil aviation, the 
monetary benefit per $\mathrm{kg}$ weight saving (at higher payloads) is estimated at $100-500 €([29,30]$ and see cases in [31, 32]).

If more than one target perspective is included, a multi-criteria decision-making (MCDM) problem arises (at least in the case of non-dominating alternatives). To handle such a problem, for instance, best solution mapping with ternary diagrams is suggested and applied, e.g. in cases $1 \mathrm{~b}$ and $1 \mathrm{c}$. Utility value analysis as a prominent MCDM method was used in case $3 \mathrm{~b}$ to calculate the economic lightweight index, which can also be seen as a means for multi-criteria decision-making since it combines two different target perspectives. Furthermore, in case $3 d$, this method forms the basis for decision-making regarding technical and economic criteria.

In most cases, the evaluation activities require the handling of a large amount of data. Besides using Microsoft Excel, a specific IT tool was developed to support the use of MEMPHIS [33]. This or similar tools can also be the basis for a profound (cost) knowledge management, which could help to systematize, to store, to use, and to transfer the necessary information. Nevertheless, in the regarded cases methods of knowledge management are not explicitly considered so far. However, a concept for managing cost knowledge for the economic evaluation of process chains for hybrid products was conceptualized and outlined with regard to case 3a [26]. Since in a research cluster such as MERGE innovative technologies are always explored and the corresponding objects go through their very early life cycle phases, the acquisition of data about products, processes, resource consumption, outputs, etc. necessary for applying the aforementioned models and methods is a central task and a considerable challenge. In the regarded cases a systematic, transparent, and unambiguous data acquisition was the aim, e.g. by using process data sheets. However, a validated, comprehensive method for data acquisition has not yet been developed. The inevitably remaining uncertainty of the data causes an uncertainty of the evaluations' results. To reveal the possible effects on the results, the scenario method as well as the sensitivity analysis can be used to enable the calculation of the range of possible outcomes of the alternatives. The sensitivity analysis was applied to cases $1 \mathrm{a}$ and $3 \mathrm{c}$, for example.

Sensitivity analysis can also be applied to derive design impulses: It allows for the calculation of values of input factors that are critical for the profitability of alternatives - and which should be achieved by further R\&D activities. In the case of cost data, this can be interpreted as a Target Costing element. In principle, the whole Target Costing methodology seems to be applicable or at least transferable to the design activities of MERGE. However, this so far has only been conceptualized (see $[4,28]$ ) and not used for a case. In order to give the design activities an economic orientation (besides the technical and/or ecological perspective) and to support innovation activities, the early elaboration and consideration of potential business models and their elements as well as the application of related methods such as the Integrated LCE and Business Modeling (BM) and the Integrated Technology, Market, and User Analysis seem to be helpful (cases of group 2) $[4,13]$. They promise to support the bridging of the gap between invention and successful innovation by aligning or even directing engineering activities towards business necessities and opportunities.

In summary, this examination shows that usually some of the existing multi-faceted methods and models were applied to a case (figure 5). This implies the need to select the appropriate methods and models as well as to integrate their use in order to avoid doubling the workload and inconsistencies. This is all the more true if the existing technically and ecologically oriented methods suggested in the framework of LCE are also taken into account. 


\begin{tabular}{|c|c|c|c|c|c|c|c|c|c|c|c|}
\hline \multicolumn{2}{|l|}{ Methods and models } & 1a & $1 \mathrm{~b}$ & 1c & $2 a$ & $2 b$ & $3 \mathbf{a}$ & $3 b$ & $3 c$ & $3 d$ & $3 e$ \\
\hline \multicolumn{2}{|l|}{ Procedure models } & $\mathrm{x}$ & $\mathrm{x}$ & $\mathrm{x}$ & $\mathrm{x}$ & $\mathrm{x}$ & $\mathrm{x}$ & & & $\mathrm{x}$ & $\mathrm{x}$ \\
\hline \multicolumn{2}{|l|}{ Life cycle models } & $\mathrm{x}$ & $\mathrm{x}$ & $\mathrm{x}$ & $x$ & $\mathrm{x}$ & & & & & \\
\hline \multirow{4}{*}{$\begin{array}{l}\text { Methods and models } \\
\text { for cost estimation/ } \\
\text { determination }\end{array}$} & Process-based models & $\mathrm{x}$ & $\mathrm{x}$ & $\mathrm{x}$ & & & & & & & \\
\hline & ITO models & & & & & & $\mathrm{x}$ & & & $\mathrm{x}$ & $\mathrm{x}$ \\
\hline & Cost estimation techniques & $\mathrm{x}$ & $x$ & $\mathrm{x}$ & & & $x$ & $x$ & $\mathrm{x}$ & $\mathrm{x}$ & $x$ \\
\hline & Cost calculation schemes & & & & & & $\mathrm{x}$ & & & $\mathrm{x}$ & $\mathrm{x}$ \\
\hline \multicolumn{2}{|c|}{ Methods of dynamic investment appraisal } & $x$ & $\mathrm{x}$ & $\mathrm{x}$ & $\mathrm{x}$ & & & & & & \\
\hline \multirow{2}{*}{$\begin{array}{l}\text { Methods and models } \\
\text { for evaluating the } \\
\text { outputs }\end{array}$} & Technical evaluation methods & & $\mathrm{x}$ & $\mathrm{x}$ & & & & $\mathrm{x}$ & $\mathrm{x}$ & $\mathrm{x}$ & \\
\hline & Profit models & $\mathrm{x}$ & & & $x$ & & & $x$ & & & \\
\hline \multirow{2}{*}{ MCDM } & Best solution mapping & & $x$ & $\mathrm{x}$ & & & & & & $\mathrm{x}$ & \\
\hline & Utility value analysis & & & & & & & $\mathrm{x}$ & & $\mathrm{x}$ & \\
\hline \multicolumn{2}{|l|}{ Sensitivity analysis } & $x$ & & & $x$ & & & & $x$ & & \\
\hline \multirow{3}{*}{$\begin{array}{l}\text { Innovation-oriented } \\
\text { methods and models }\end{array}$} & Integrated LCE and BM & & & & $x$ & $x$ & & & & & \\
\hline & $\begin{array}{l}\text { Integrated Technology, Market, } \\
\text { and User Analysis }\end{array}$ & & & & & $x$ & & & & & \\
\hline & Business modeling & & & & $x$ & $x$ & & & & & \\
\hline
\end{tabular}

Figure 5: Application cases of management-oriented and life cycle-related methods and models in MERGE

\section{Potentials and challenges}

The potentials of using management-oriented and life cycle-related methods and models in early life cycle phases and in close conjunction with engineering methods can be distinguished into direct and indirect effects. Direct effects stem from the results of the methods' application: In the cases of an economic evaluation, they reveal the advantageousness of alternatives from an economic perspective, give indications for critical levers that should be focused in engineering activities, point to critical values of these levers, and show the range of potential target values if uncertainty is included. If other target perspectives are additionally considered, the relationship between the achievement of economic and other targets can be disclosed and an integrated evaluation of sustainability can be facilitated. Concerning design tasks, the focus is on market potentials, user needs, potential business ideas, value propositions, supply chain activities, supply chain partners, etc. Such direct effects are particularly valuable in the early life cycle phases due to the huge potential of improvement that exists there.

Indirect effects are more overarching. The application of the methods sensitizes for economic aspects, contributes to a common understanding of the engineering (and management) task, allows for a neutral view on the explicit or implicit assumptions made by engineers and helps to secure the reliability and completeness of the input data and the corresponding assumptions. The last effect mainly results from questioning for the data necessary for economic considerations. This questioning and the economically motivated modeling also contribute to building quantitative models for the resource consumption as a function of process parameters and output. Furthermore, pressure to systematically disclose and exploit the utility potentials of new technologies, which can be contrasted with the resulting costs, is generated. Finally, an interdisciplinary systems engineering competence is built up that may, among other things, be helpful for the acquisition of further projects (this was used for the further development and market introduction of active flow control devices in rotor blades of wind turbines (project "Technologische und ökonomische Betrachtung der Anwendung aktiver Strömungskontrolle zur Optimierung der Winderntefähigkeit von Windenergieanlagen" - TOpWind) as well as for the constitution of a research, development, and innovation center for smart rail traffic ("Smart Rail Connectivity Campus")). 
However, direct and indirect challenges have to be considered as well (for similar insights from a research cluster see [34]). One "direct" challenge is the effort of the analyses and especially the acquisition of the necessary data and the construction of concrete models for evaluation, especially in a research context. Coupled with this challenge, the challenge of uncertainty typically arises due to the relevance of different life cycle phases (including usage and end-of-life), the novelty of the technologies and the application in the early life cycle phases. These effects are reinforced by the complexity and diversity of the objects to be evaluated and designed, which also hinders the transparency of the calculations. Approaches for handling these challenges are the definition of usage and end-of-life scenarios, the already mentioned explicit inclusion of uncertainty, a repeated application along the engineering phase (and the following life cycle phases), a transparent documentation of assumptions and formulas, and a careful interpretation of the results considering the uncertainty. In order to limit the efforts, more generic product or process models for types of objects would be helpful. Finally, knowledge management systems could help to substantially improve the database.

A considerable "indirect" challenge is the necessity of interdisciplinary work. To perform the evaluations, knowledge from different domains was required - of course from the economic and engineering domain, but in some cases even from different engineering sub-domains (related to materials, processes, and/or production systems). On the one hand, this implies the need to build interdisciplinary teams to provide the different competencies. On the other hand, intense and error-free communication between the experts has to be ensured. Exact, consistent, and clear definitions and methods are therefore helpful.

\section{Conclusion and Agenda for Life Cycle Engineering and Management}

Within the Cluster of Excellence MERGE several management-oriented and life cycle-related methods and models were developed, refined, and applied. By using these methods and models in conjunction with engineering methods in different cases, their applicability and usefulness for evaluating the (economic) advantageousness of alternatives and deriving evaluation-based indications for the design were shown. Hence, a resource-efficient lightweight design and particularly the design of hybrid structures as well as the bridging the gap between invention and successful innovation can be supported by these methods and models.

However, the cases revealed some major challenges for a successful application as well: To exploit the full potential of the methods and models or rather of LCE and LCEM, they should be applied early in the life cycle and accompany research and development - but especially in these life cycle phases it is extremely difficult to make significant and reliable data available. Furthermore, the methods and models have to be specifically selected and adapted for the different cases, which constitutes a tension between the intended support by a generally applicable methodology and the need for a case-specific "customization".

The insights generated by the application of management-oriented and life cycle-related methods and models in MERGE allow for an agenda for further research to be derived:

- The approaches, concepts, and methods have to be further elaborated and "validated". This includes the extension of Target Costing to a Target Outcome-based Engineering with other target perspectives, the integration of engineering and business modeling, the stronger integration of supply chain issues, better support of data acquisition processes and finding the balance between standardization and customization of methods and models.

- Other previously neglected management issues such as knowledge management, leadership, culture, organization, and individual human resources should be integrated into or with LCE(M).

- The aim should be to create a common theoretical basis: towards a theory of engineering and management (including common definitions, research approaches, integrated methodologies, etc.).

- The teaching of or education in $\operatorname{LCE}(\mathrm{M})$ should be strengthened in order to broaden the competence base. 
- Empirical studies should reveal the practices of $\operatorname{LCE}(M)$, the factors favoring and hindering the implementation of LCE(M) as well as the success factors for life cycle- and technology-related innovations.

\section{Acknowledgements}

This work was carried out within the framework of the Federal Cluster of Excellence EXC 1075 "MERGE Technologies for Multifunctional Lightweight Structures" and supported by the German Research Foundation (DFG). The financial support is gratefully acknowledged.

This work was carried out as part of the program "PPP Portugal", the projects "Life Cycle Engineering and Management Framework" and "Enhancement of Life Cycle Engineering Methodology by Integration of Management-related Methods and its Application to Complex Systems" and is partially supported by the DAAD with funds of the German Federal Ministry of Education and Research.

\section{References}

[1] Carlowitz, H.C. von: Sylvicultura Oeconomica oder Haußwirthliche Nachricht und Naturmäßige Anweisung zur Wilden Baum-Zucht. Leipzig: Braun, 1713 (German).

[2] Jeswiet, J.: A Definition of Life cycle engineering. In: Bley, H. (ed.): Proceedings of the $36^{\text {th }}$ CIRP International Seminar on Manufacturing Systems, Saarbrücken, Schriftenreihe. Produktionstechnik, Band 29. Saarbrücken: Universität des Saarlandes, 2003, pp. 17-20.

[3] Peças, P. et al.: Life Cycle Engineering - Taxonomy and State-of-the-art. In: Procedia CIRP, 48 (2016), pp. 73-78. doi: 10.1016/j.procir.2016.04.085

[4] Götze, U. et al.: Life Cycle Engineering and Management - Fostering the Managementorientation of Life Cycle Engineering Activities. In: Procedia CIRP, 61 (2017), pp. 134-139. doi: 10.1016/j.procir.2016.11.240

[5] Peças, P. et al.: A Life Cycle Engineering model for technology selection: a case study on plastic injection moulds for low production volumes. In: Journal of Cleaner Production, 17 (2009) 9, pp. 846-856. doi: 10.1016/j.jclepro.2009.01.001

[6] Umeda, Y. et al.: Toward integrated product and process life cycle planning - An environmental perspective. In: CIRP Annals - Manufacturing Technology, 61 (2012) 2, pp. 681-702. doi: 10.1016/j.cirp.2012.05.004

[7] Hauschild, M. Z. et al.: An Integrated Framework for Life Cycle Engineering. In: Procedia CIRP, 61 (2017), pp. 2-9. doi: 10.1016/j.procir.2016.11.257

[8] Götze U. et al.: Integrated Framework for Life Cycle-Oriented Evaluation of Product and Process Technologies: Conceptual Design and Case Study. In: Henriques, E. et al. (eds.): Technology and Manufacturing Process Selection: The Product Life Cycle Perspective. London: Springer, 2014, pp. 193-215.

[9] Ribeiro, I. et al.: Fostering selection of sustainable manufacturing technologies - A case study involving product design, supply chain and life cycle performance. In: Journal of Cleaner Production, 112 (2016) 4, pp. 3306-3319. doi: 10.1016/j.jclepro.2015.10.043

[10] Carvalho, H. et al.: Application of Life Cycle Engineering approach to assess the pertinence of using natural fibers in composites - the rocker case study. In: Procedia CIRP, The 23rd CIRP Conference on Life Cycle Engineering, 48 (2016), pp. 364-369. doi: 10.1016/j.procir.2016.03.144

[11] Wübbenhorst, K. L.: Konzept der Lebenszykluskosten - Grundlagen, Problemstellungen und Technologische Zusammenhänge. Darmstadt: Verlag für Fachliteratur, 1984 (German).

[12] Götze, U. et al.: Life cycle-oriented analysis and evaluation of Active Flow Control in wind turbines. In: International Journal of Condition Monitoring and Diagnostic Engineering Management, 18 (2015) 3, pp. 11-20.

[13] Götze, U. et al.: Integrierte Geschäftsmodell- und Technologieentwicklung für smarte Systeme und Strukturen. In: Wiedemann, M.; Melz, T. (eds.): Smarte Strukturen und Systeme, 
Tagungsband des 4SMART-Symposiums, 21.-22. Juni 2017, Braunschweig. Aachen: Shaker, 2017, pp. 401-413 (German).

[14] Großmann, T.D. et al.: Realisation of Sensitive Functionality by the Integration of Electromagnetic Resonators in Composite Materials. In: Technologies for Lightweight Structures, 1 (2017) 2, pp. 138-146. doi: 10.21935/tls.v1i2.90

[15] Großmann, T.D. et al.: Remote ice detection on rotor blades of wind turbines. In: Kroll, L. (ed.): 2nd International MERGE Technologies Conference, Chemnitz, Conference Proceedings. Auerbach: Wiss. Scripten, 2015, pp. 265-271.

[16] Symmank, C. et al.: Life cycle engineering and evaluation of hybrid products and manufacturing processes, Global Cleaner Production and Sustainable Consumption Conference, Sitges, Spain, 2015.

[17] Symmank, C. et al.: Holistic Evaluation of Process Chains for Resource-Efficient Manufacturing of Hybrid Structures. In: Landgrebe, D. et al. (eds.): 5th International Conference on Accuracy in Forming Technology, Reports, Proceedings, Reports from the IWU, ICAFT 2015. Auerbach: Wiss. Scripten, vol. 88, 2015, pp. 457-476.

[18] Walther, M. et al.: An Economic Lightweight Concept for the evaluation of thermoplastic foams for aerodynamic lightweight structures. In: International Journal of Condition Monitoring and Diagnostic Engineering Management, 19 (2016) 1, pp. 11-15.

[19] Schüller et al.: Design of synthetic jet actuators for the integration into lightweight structures and economic evaluation of alternative actuator manufacturing technologies. 3rd International MERGE Technologies Conference, IMTC 2017 Lightweight Structures, Chemnitz, 2017, pp. 109-110.

[20] Trautmann, M. et al.: Comparison of manufacturing fiber metal laminates based on thermoplastic and thermosetting material: Analyses of mechanical properties and economic effects. 3rd International MERGE Technologies Conference, IMTC 2017 Lightweight Structures, Chemnitz, 2017, pp. 19-20.

[21] Symmank, C. et al.: Methodology for the early analysis and evaluation of the resource efficiency of process chains for manufacturing hybrid structures. In: Procedia Manufacturing, 33 (2019), pp. 430-437. doi: 10.1016/j.promfg.2019.04.053

[22] Götze, U. et al.: Zur Analyse und Bewertung von Produkt-Prozessketten-Kombinationen der hybriden Produktion. In: Neugebauer, R. et al. (eds.): Energetisch-wirtschaftliche Bilanzierung Diskussion der Ergebnisse des Spitzentechnologieclusters eniProd. Auerbach: Wiss. Scripten, 2014, pp. 21-32 (German).

[23] Katzenberger, J. et al.: Manufacturing of hybrid structures - Multidimensional analysis for resource-efficient processes. In: Proceedings EuroHybrid Materials and Structures 2014, Stade, 2014, pp. 172-181.

[24] Schüller, M. et al.: Integration concept for fluidic actuators in hybrid structures. In: Proceedings of the Smart Systems Integration Conference 2014, Glasgow, 2014.

[25] TU Chemnitz.

[26] Köhler, S. et al.: Economic evaluation of process chains for hybrid products - concept for managing cost knowledge. In: Seliger, G. et al. (eds.): Procedia Manufacturing: $14^{\text {th }}$ Global Conference on Sustainable Manufacturing, 03.-05.10.2016, Stellenbosch, South Africa, 8 (2017), pp. 587-594. doi: 10.1016/j.promfg.2017.02.075

[27] Ehrlenspiel, K. et al.: Cost-Efficient Design. Berlin, Heidelberg: Springer, 2007.

[28] Großmann, T.D. et al.: Realisierung von smarten Strukturen mit sensorischer Funktion durch Integration elektromagnetischer Resonatoren in hybride Materialien. In: Wiedemann, M.; Melz, T. (eds.): Smarte Strukturen und Systeme, Tagungsband des 4SMART-Symposiums, 21.-22. Juni 2017, Braunschweig. Aachen: Shaker, 2017, pp. 119-129 (German).

[29] Reuter, M.: Methodik der Werkstoffauswahl. 2nd ed. München: Hanser, 2014 (German).

[30] Ashby, M.F.: Materials Selection in Mechanical Design. 5th ed. Amsterdam: ButterworthHeinemann, 2017.

[31] Landgrebe, D. et al.: Evaluation of manufacturing processes for the production of graded ultrafine grained materials. In: Procedia Manufacturing: 15th Global Conference on Sustainable 
Manufacturing, 25.-27.09.2017, Haifa, Israel, 21 (2018), pp. 45-52. doi: 10.1016/j.promfg.2018.02.093

[32] Herold, F. et al.: Technical-economic evaluation of severe plastic deformation processing technologies - methodology and use case of lever-arm-shaped aircraft lightweight components. In: The International Journal of Advanced Manufacturing Technology, 94 (2018), pp. 3619-3632. doi: 10.1007/s00170-017-0921-x

[33] Grzelak, D. et al.: Requirements and design concepts of a software tool for a multidimensional analysis of process chains. In: Kroll, L. (ed.): $2^{\text {nd }}$ International MERGE Technologies Conference, Chemnitz, Conference Proceedings. Auerbach: Wiss. Scripten, 2015, pp. 339-341.

[34] Neugebauer, R.; Götze, U.: Energetisch wirtschaftliche Bilanzierung und Bewertung Herausforderungen und Erkenntnisse. In: Neugebauer, R. et al. (eds.): Energetischwirtschaftliche Bilanzierung - Diskussion der Ergebnisse des Spitzentechnologieclusters eniProd. Auerbach: Wiss. Scripten, 2014, pp. 1-9 (German). 